أسباب عزوف الطلاب عن المشاركة في النشاط

\author{
إعداد \\ الباحث / عبد|لعزيز محمد نعيم
}

مجلة بحوث التربية النوعية - جامعة المنصورة

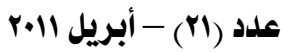




\title{
أسباب عزوف الطلاب عن المشاركة في النشاط
}

\author{
إعداد \\ الباحث / عبد العزيز محمد نعيم
}

الإقدهمة

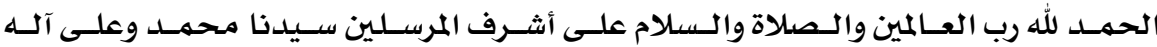

وصحبـه أجمعين .

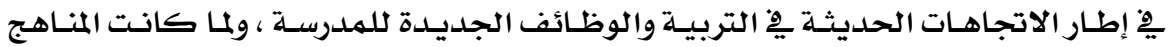

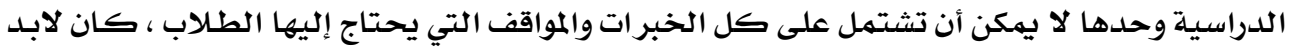

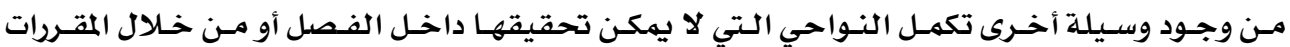

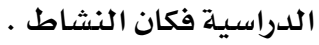

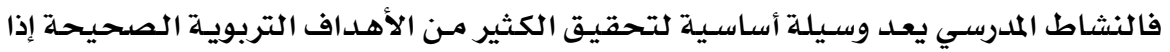

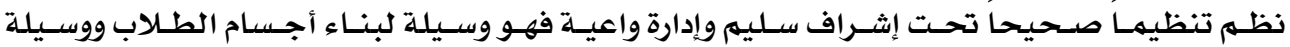

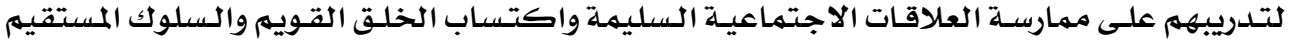

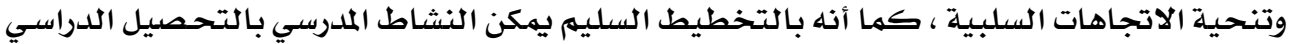

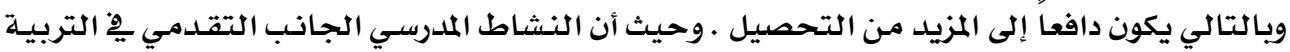

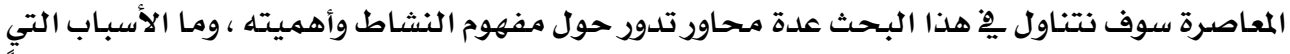

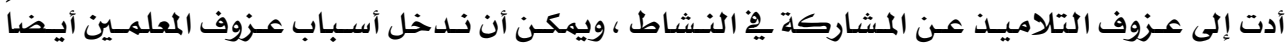
والحلول المقترحة ، وسوف نسعى جاهدين أن نتناول هذه المثكلة من جميع جوانبها .

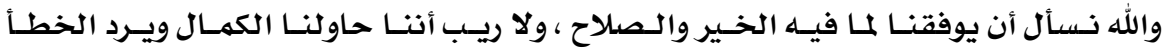

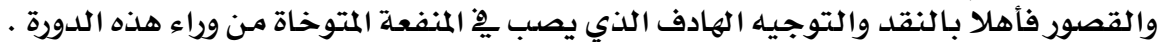
والله من وراء القصد

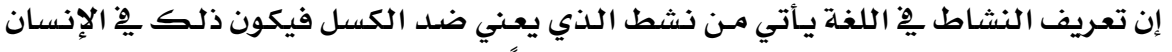

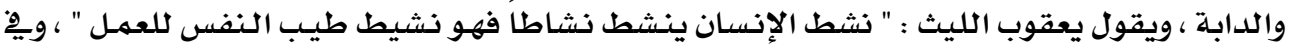

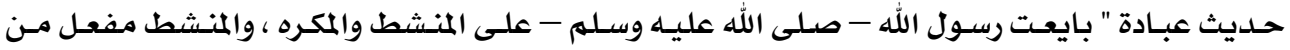

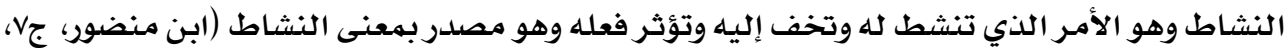

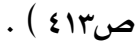

ويعرف مجمـع اللغـة النشاط بأنه الممارسـة الصادقة لعمل من الأعمال " مجمهـع اللغلة جץ " .

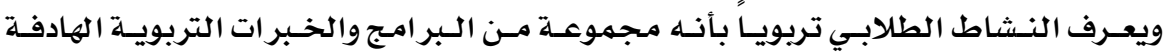

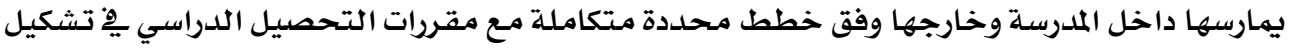




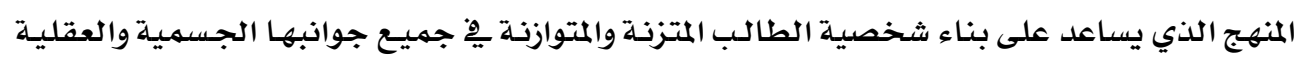

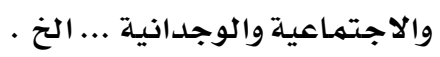

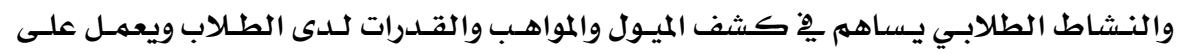

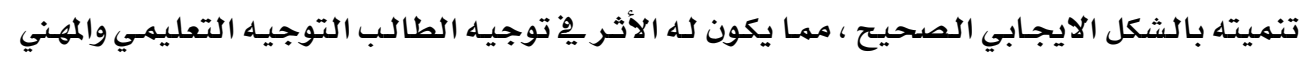

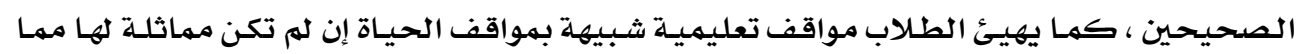

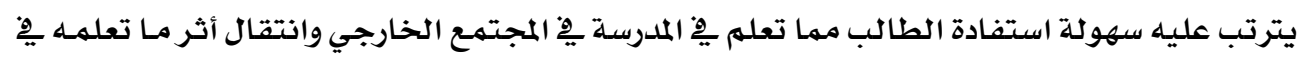
حياته المستقبلية .

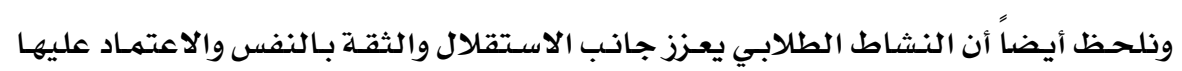

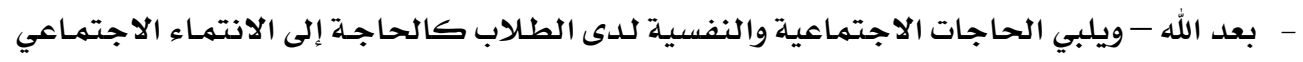

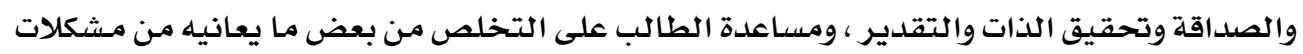

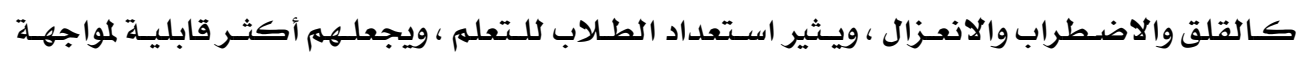

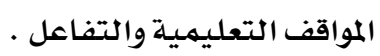

إلا أن العـزوف عـن النـشاط لـيس على مـستوى الطـلاب بـل هـو أكثـر إلى بعض المعلهـين

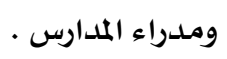

ومعرفة المثكلات التي تواجه ممارسة الأنشطة أمر ضروري وأساسي لتذليلها ومعرفة السبل

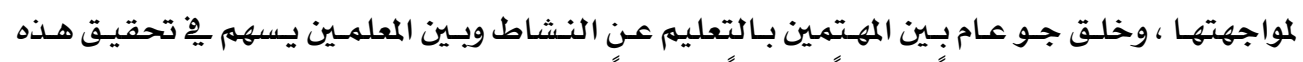
الأنشطة وتحديثها تخطيطاً وتنفيذاً وتقويماً وتوظيفاً .

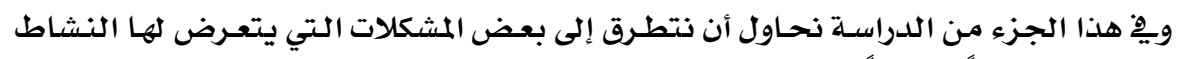

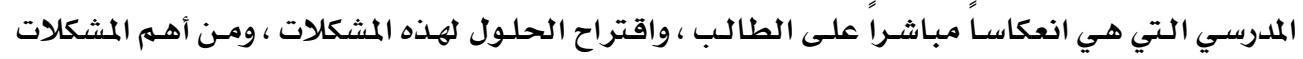

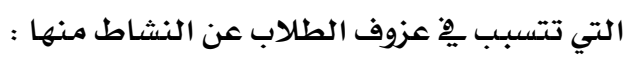

\section{اـ علدم الإيمان الحقيقي بقيمة النشاط وأهميته :}

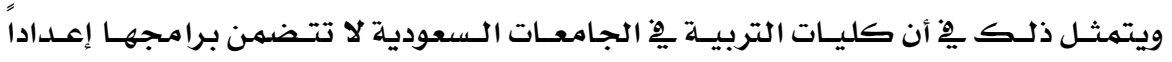

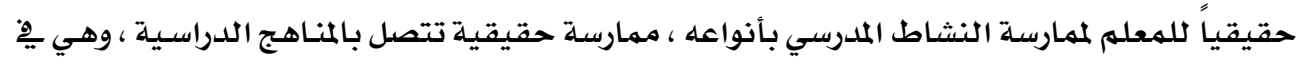

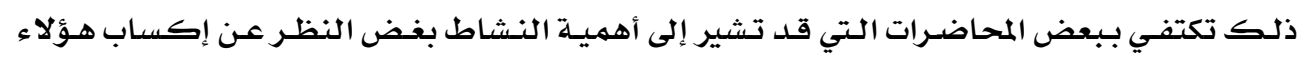

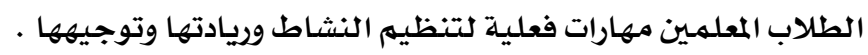

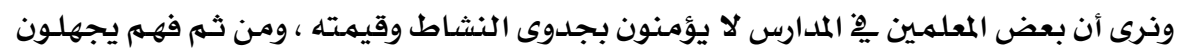

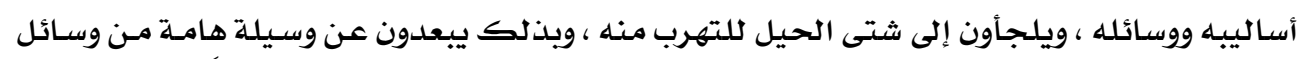

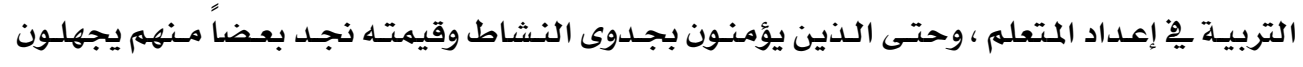

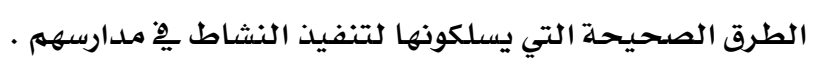

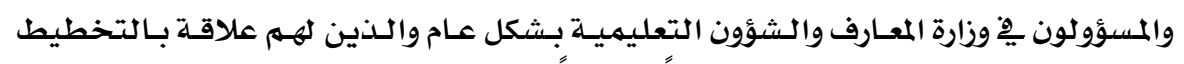

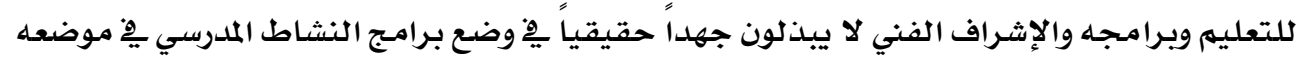


الصحيح من الخطة الدراسية ، أو توفير الإمكانات المناسبـة لممارستها أو تـدريب المعلمـين لممارسسة هـذه

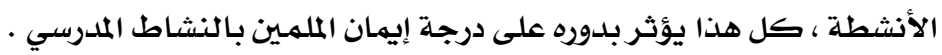
rـ علدم تفهم بعض مليري المدارس الأهلية النشاط :

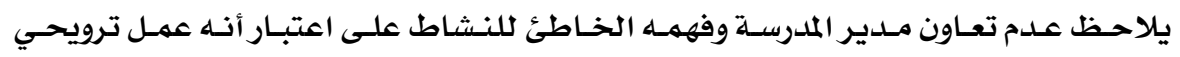

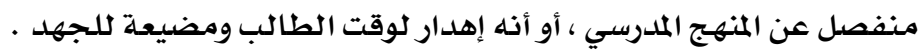

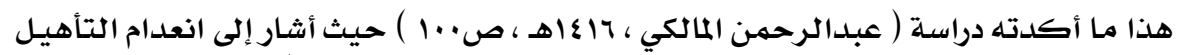

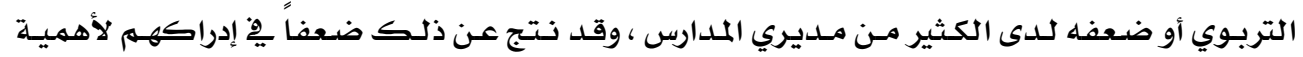

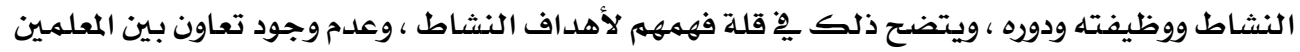

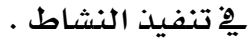

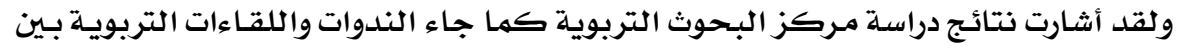

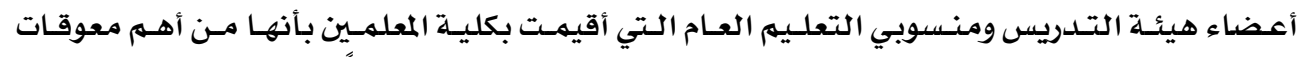

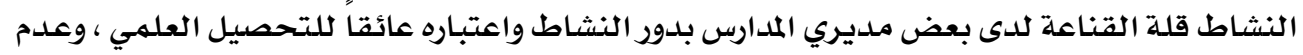

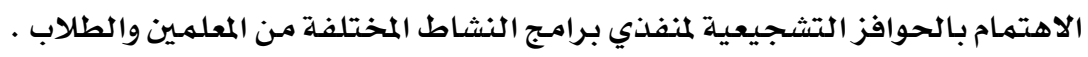

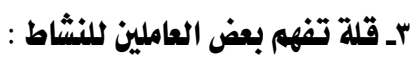

يعتبر المعلم الركيزة الأساسيـة يف العمليـة التعليميـة ، وهو حجز الزاويـة ونقطة الانطلاق

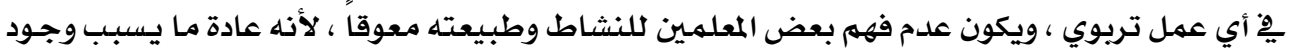

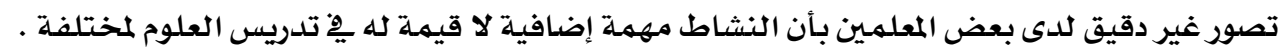

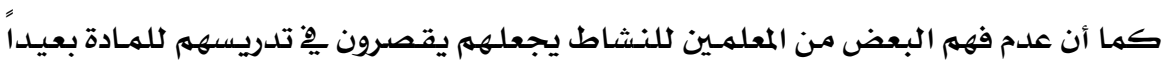

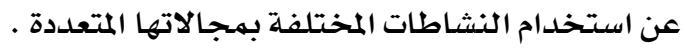
وقد يؤدي عدم فهم بعض المعلمـين للنشاط جعل أن النشاط مسؤولية إدارة المدرســة ومسشرف

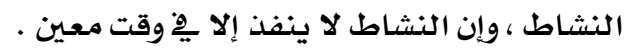

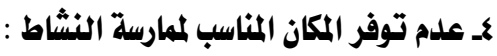

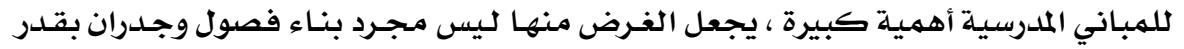

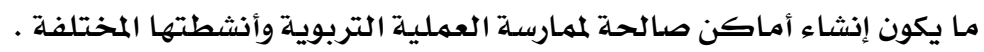

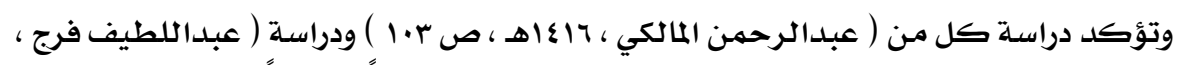

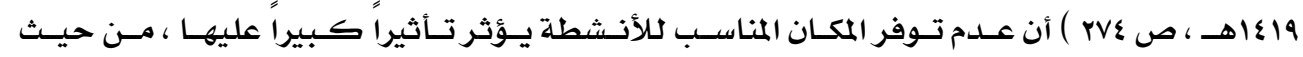
تقليص مجالاتها .

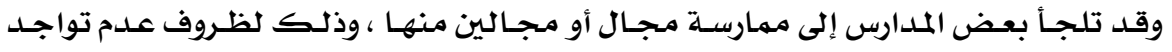

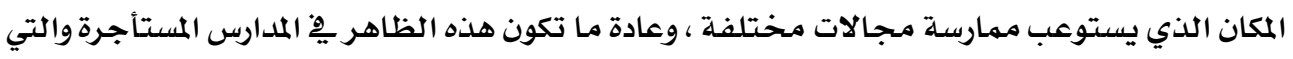

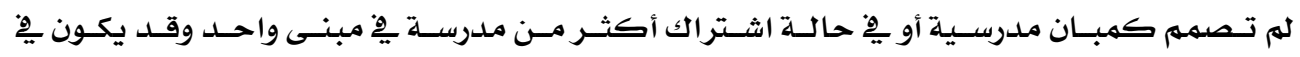
فترة واحدة . 
والأنشطة بحاجة إلى ساحات وملاعب وقاعات ، وعدم وجود أو نقص هـذه المرافق يؤثر تأثيراً

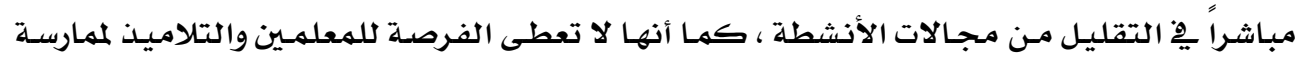

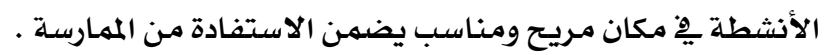

وعدم توفر المكان المناسب عائق يواجه كثير من الدول التي تعتمد على المباني المستأجرة .

\section{0ـ نقص الإمكانات المادية للنشاط : وعرد المان}

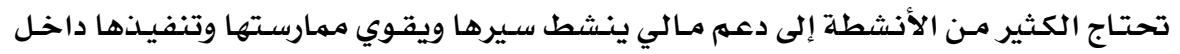

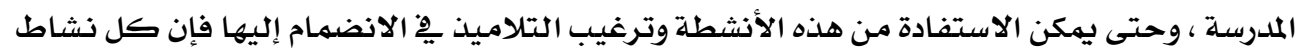

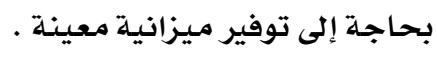

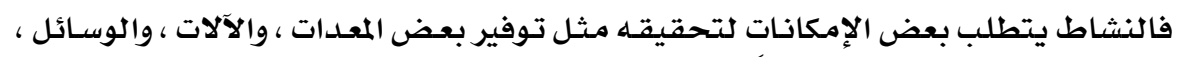

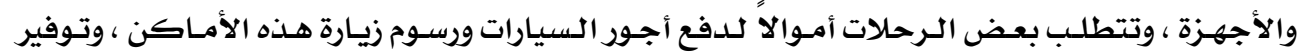

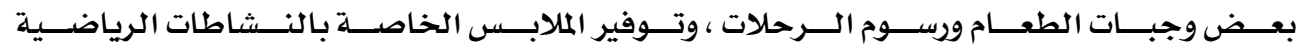

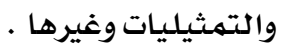

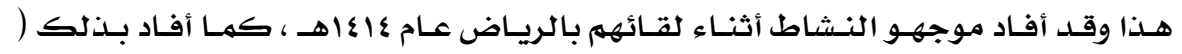

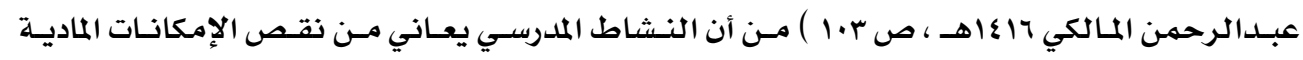

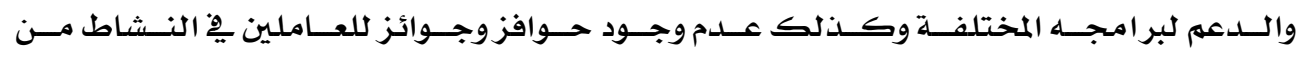

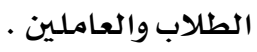

7ـ قلة ارتباط النشاط الملدرسي بالمنهج الدراسي :

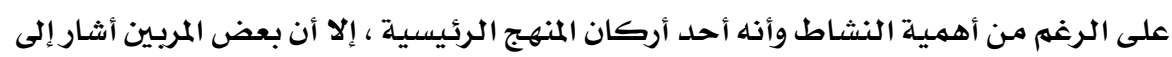

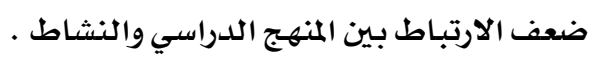

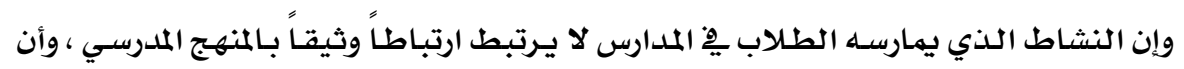

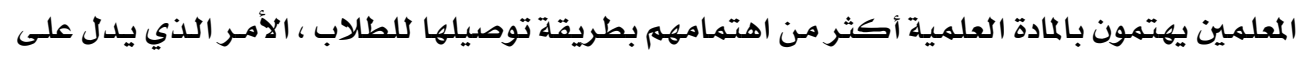

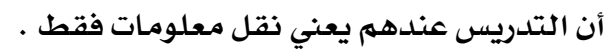

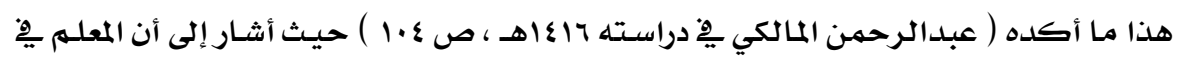

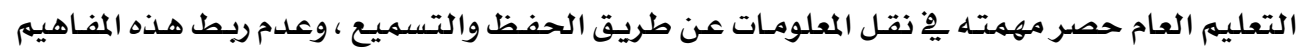

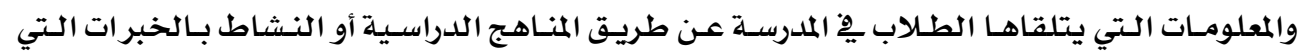

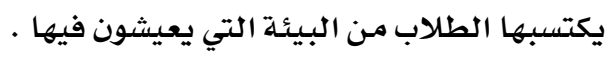

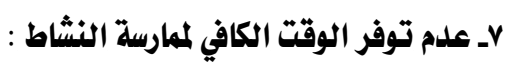

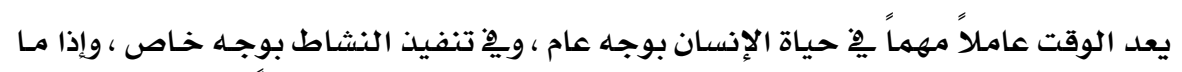

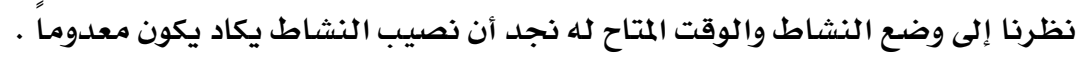

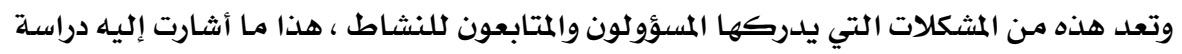

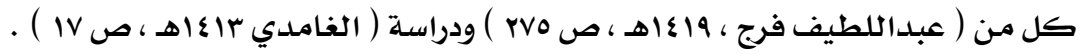




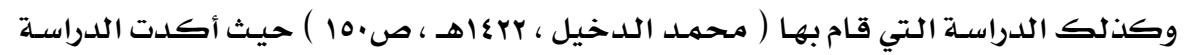

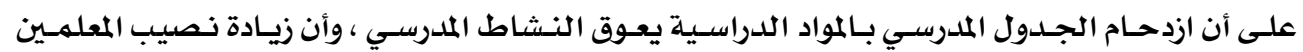

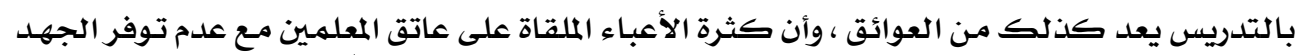

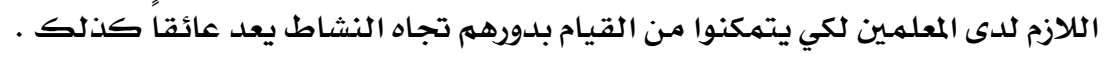

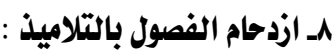

إن ازدحام الفصول بـالتلاميذ يِّ الآونة الأخيرة أضعف من مهارسـة ألوان عديـدة مـن النشاط

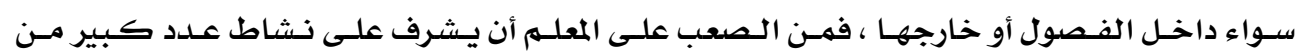
التلاميذ داخل الفصل الواحد ، كما أن الأعمال الإداريـة الكثيرة التي قد تسندها الملدرسـة للمعلـم ومـا

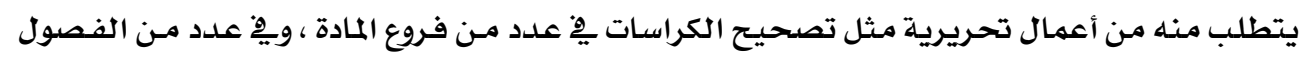

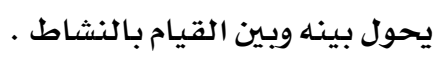

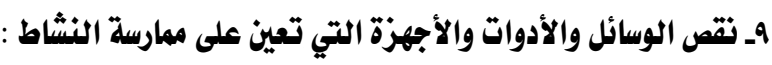

للوسـائل التعليميـة أهميـة بـالغـة فِ التدريس وفِ تنشيط المعنى للطلاب وفِ تصوير المعاني

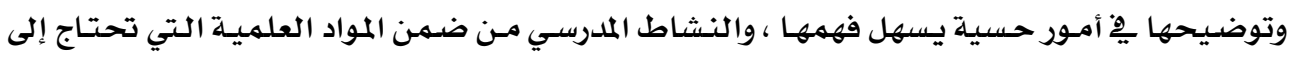

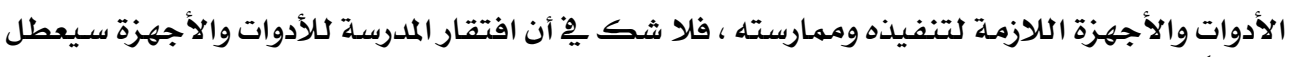
كثيرا من الأنشطة ، فالأنشطة الرياضية تحتاج إلى أدوات تهارس بها أنشطتها وتمارينها الرياضيـة ، والرياضدة البدنية ليست كرة قدم فقط ، كما تحتاج بعض الأنشطة إلى المال فالزيـارات أو الرحلات

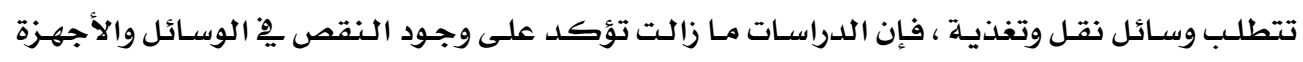

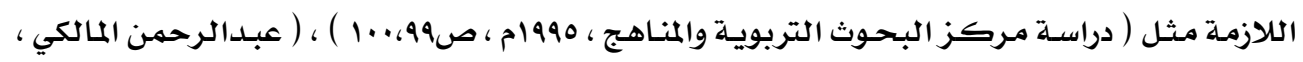

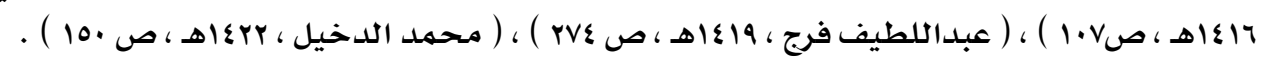
•اـ علدم قدرة المعلمين على تنظيه الأنشطة وريادتها :

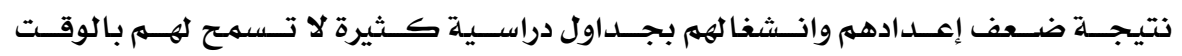

$$
\text { والجهد الكلازمـين . }
$$

\section{الـ علدم تعاون المعلمين بالملدرسة وتقاوتهم في وجهات النظر :}

بخصوص النشاط المدرسي وأهميته يخ العملية التربوية ، واهتمامهم الزائد بـالجـانب المعربِ دون سواه .

rاـ علدم العناية بالنشاط في تقويه الطالاب والمعلمين :

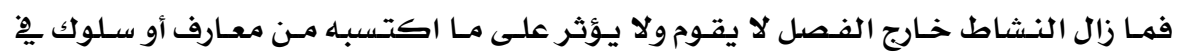

$$
\text { تقدير نجاحه أو فثلهه . }
$$

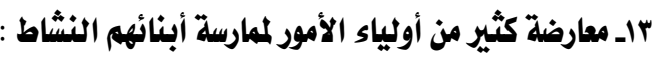
على أنه يعطلهم عن عملية تحصيل المعارف والتي هي الهدف الأسـاسي للمدارس . 
يمكن الاسترثاد بـه عند التخطيط لها ل

10ـ نظام الامتحانات والاهتمام بها اهتماماً مبالفاً فيه :

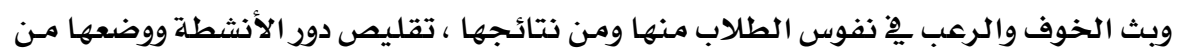

الناحية العملية يِّ مرتبة متأخرة من الأهمية .

17 اـ انخفاض الروح المعنوية لدى المعلمين والطلاب :

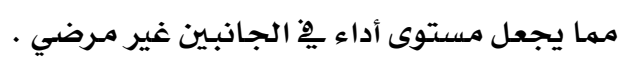

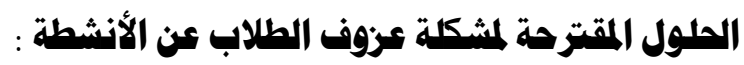

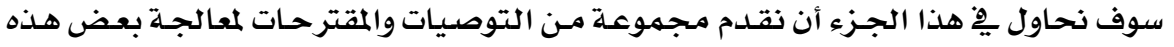

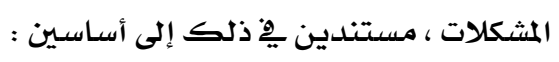

أولاً : العوامل التي كشفت عنها الدراسة الميدانية التي قام بها الدكتور محمد إبراهيم الدخيل .

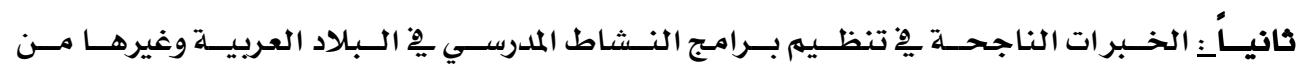

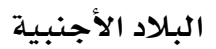

(ا) حلول مقتزحة تتعلق بالمعلم : وهي :

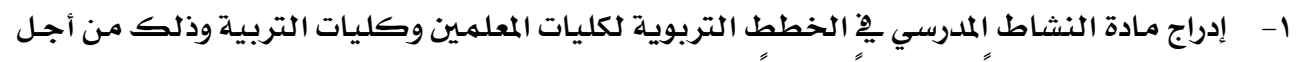

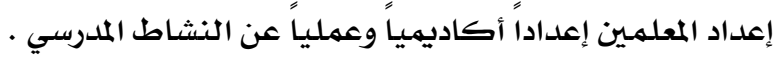

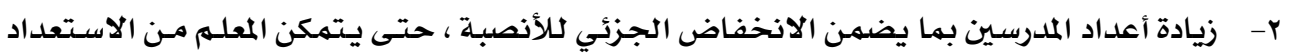

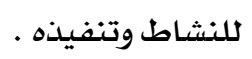

r- تخصيص حوافز مادية ومعنوية للمشرفين عن النشاط من قبل إدارة التعليم •

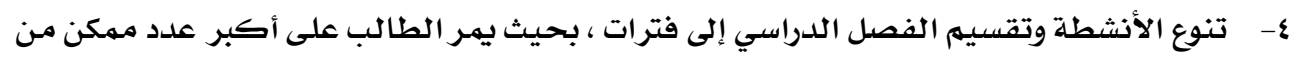
الأنشطة التي تناسب ميوله واهتماماته .

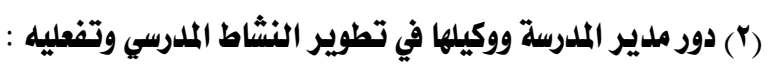

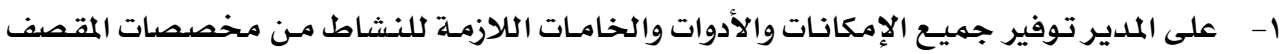

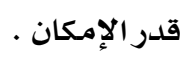

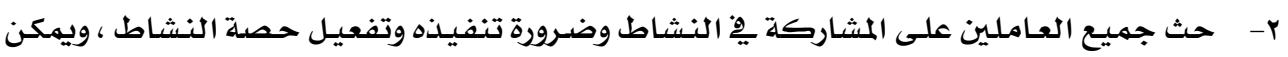

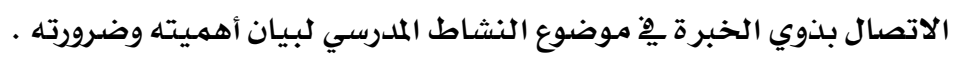

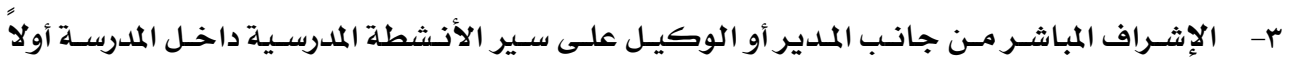

$$
\text { بأول وتقويمها . الأشراف المباثر }
$$

ع- تخصيص معرض دائم لعرض إنتاج الأنثطة التي يقوم بها الطلاب . 


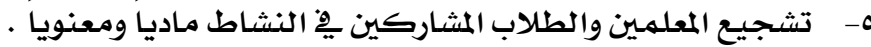
7- الاختيار المناسب لمشرف النشاط بالمدرسة على حسب قدراته واستعداداته . . (r) اللدور المتوقع من إدارة التعليه في تطوير النشاط الملدرسي وتفعيله :

1- حث جميع المدارس بالمنطقة على تفعيل حصة النشاط وإبرازها . r - إقامـة دورات مكثفة لرواد النشاط الطلابي بالمنطقة . r- زيادة أعداد المدرسين بالمدارس بما يضمن الانخفاض الجزئي لكلأنصبـة . ع- متابعة تفعيل النشاط بالمدارس من خلال التقويم النهائي لها . 0- تقديم الحوافز المادية والمعنوية للمدارس الفائزة يٌْ الأنثطة . . 7- تزويد المدارس بالنشرات والتعاميم الخاصدة بالنشاط المدرسي .

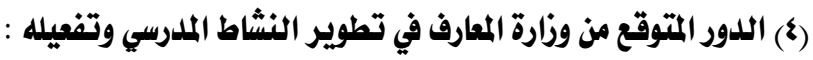
1- إعداد دليل عام للمدارس على مستوى المملكة يوضح النشاط المدرسي وأهميته . r- تخصيص قدر من الدرجات للنشاط المدرسي ، حتى يهتم به كل معلهم وطالب . r- إصدار توجيهات لإدارات التعليهم بتخفيض نصاب المعلهم المكلف بالنشاط المدرسي .

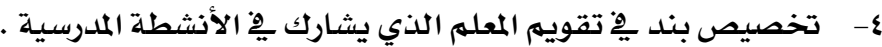
:

1- ضرورة توضيح أهداف النشاط بحيث يدركها كل من علاقة بالتربية .

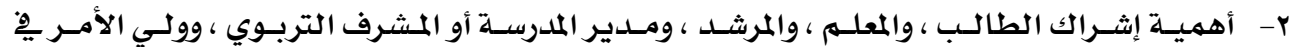

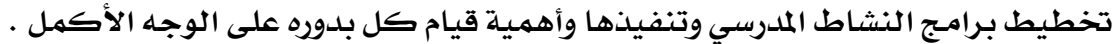

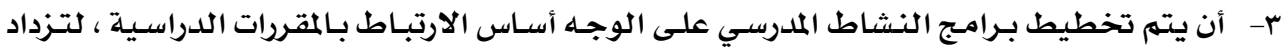

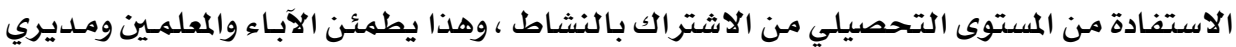
المدارس ويشعرهم بفضل النشاط ِِِ الإعانـة على تحقيق الهـدف التحصيلي ، الـذي يضعونه يِ مكانه عالية . ع- اختلاف طريقة التنفيـذ بـين منطقـة تعليميـة وأخـرى يثري العمـل خاصـة إذا كان هنـاك زيـارات

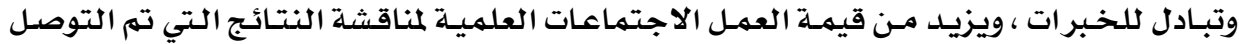

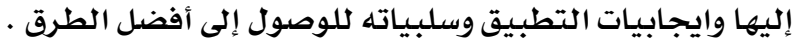

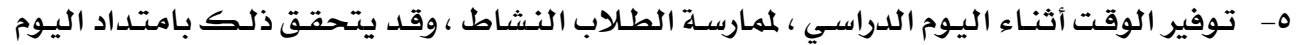

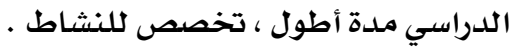

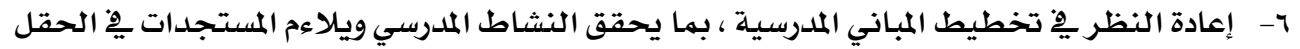
التربوي • 


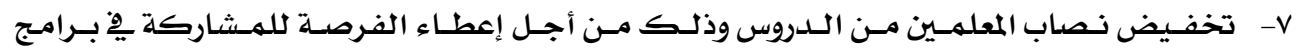
النشاط المختلفة .

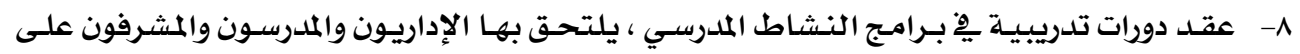

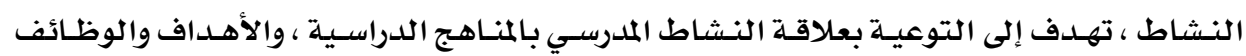
التربويـة ، التي يهكن أن تتحقق من خلال برامج النشاط كمها تهدف إلى التوعية بـالمبادئ التربوية

التي ينبغي أن يتم تخطيط البر امج وتنفيذها وتقويهها على ضوئها .

9- استعمال الحوافز ، حتى يقبل المعلمون على الإثـراف على جماعـات النشاط ، وإعطائهمه مكافآت

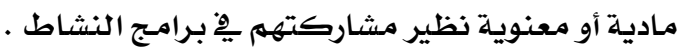

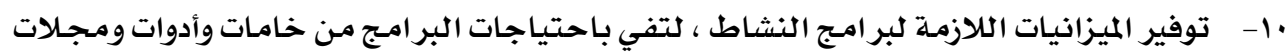
وحاجات أخرى .

ا - توعية أولياء الأمور لحث أبنائهم على المشاركة يِ الأنشطة المدرسية المختلفة .

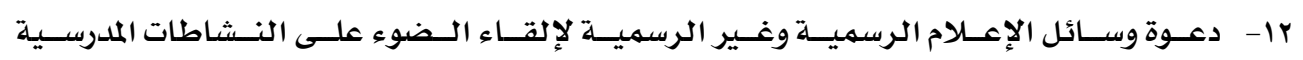

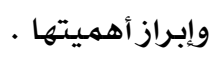

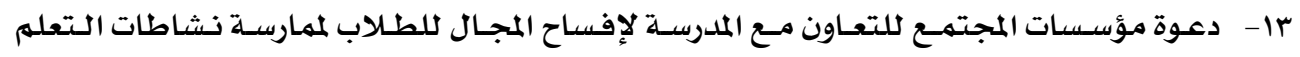

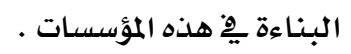

عا - توثيق العلاقة بين المدرسـة والمنزل ، وذلك عن طريق البر امـج التوعويسة التي تقـوم بها المدرسسة ،

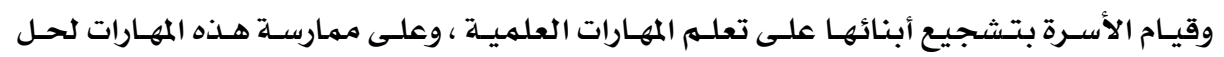
مشكلات البيئة وتوفير الوسائل البسيطة المتوافرة يخ البيئة لممارسـة التعلم .

\section{الخفاتمة}

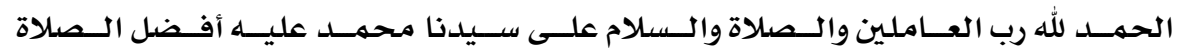
وأزكى السلام ·

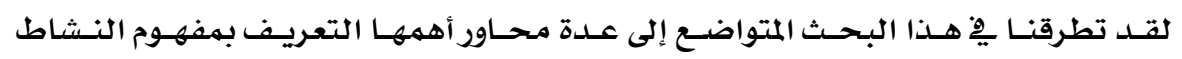

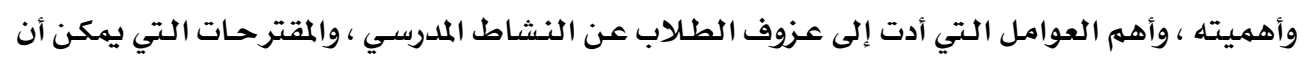

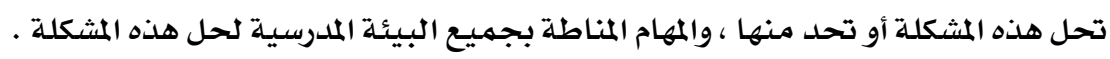

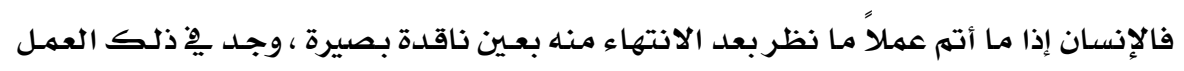

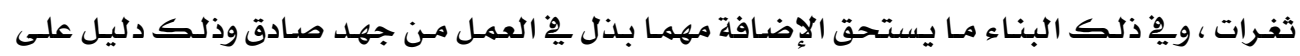
قصور الإنسـان وبعده عن الكمال ... فسبـحان من تفرد بغايات الكمال وحلده .

هذا ونثكر الله العلي القدير أن وفقنا لهذا العمل وأن يكون عملنا هذا لله ، وأن ينفعنا بـه .

$$
\text { والحمد لله رب العالمين }
$$


1- مشكلات وقضايا تربوية معاصرة :

صالح سالم باقارث ، عبدالله الآنسى معاصئ

r- النشاط المدرسي وعلاقة الملدرسة بالمجتمع :

د / محمد الدخيل

r- النشاط المدرسي ومعوقاته :

د / محمد الدخيل

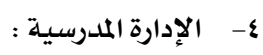

د / مليمان الحقيل

$$
\text { ه- النشاط المدرسي : }
$$

د / حسن شحاته

צ- دليل النشاط الطلابي :

وزارة المعارف

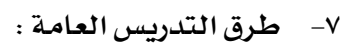

محمد عبدالقادر أحمد

^- المناهـج وطرق التدريس :

د / عبداللطيف فرج

9- النشاط المدرسي وتشتت المفهوم :

نجاة الصائغ 